\title{
Feedback and repetition as a tool to rehabilitate time perception in Korsakoff's syndrome: a case study
}

\author{
Mohamad EL HAJ, and Jean-Louis NANDRINO \\ Univ. Lille, CNRS, CHU Lille, UMR 9193 - SCALab - Sciences Cognitives et Sciences Affectives, F-59000 Lille, France
}

\begin{abstract}
The present study assesses the effect of repetition and feedback on time reproduction in a participant with Korsakoff's syndrome. The procedure consisted of three subsequent trials for each of five time intervals $(5,10,20,30$, and 40 seconds). In each trial, the participant was asked to fix a cross that was displayed in the center of a screen for 5, 10, 20,30, or 40 seconds; afterward, he was asked to reproduce the duration of the display. At the end of each trial, the participant was provided with 1) feedback on the difference between his reproduced interval and the reference interval and 2) an invitation to comply, as far as possible, with the reference interval in the next trial. The results showed under-reproduction of the five time intervals in all three trials. Interestingly, the participant demonstrated a reduction in the difference between his reproduced time and the real one (i.e., an improvement in time reproduction) across the three trials for the 5, 10, and 20 second intervals, but not for the 30 or 40 second intervals. These findings demonstrate not only time distortions in a patient with Korsakoff's syndrome, but also the beneficial effect of repetition and feedback for the reproduction of short intervals.
\end{abstract}

\section{Introduction}

Korsakoff's syndrome is a form of alcohol-related brain damage, which results from a combination of heavy alcohol consumption and thiamine deficiency [1,2]. On a neurological level, the syndrome is characterized by widespread brain shrinkage affecting the anterior nucleus of the thalamus, the mammillary bodies, the corpus callosum, and the frontocerebellar loops [3-7]. On a cognitive level, the most essential characteristic of Korsakoff's syndrome is profound anterograde amnesia, affecting the ability to learn new information $[1,2]$. The syndrome is also associated with retrograde amnesia, affecting the ability to retrieve remote memories [1,2]. Another cognitive characteristic of the syndrome is confabulations [8], which are fictitious memories without intent to deceive [9]. Besides compromised memory, the syndrome is associated with executive dysfunction [10] impacting the patients' ability to plan, organize information and think flexibly.

Another cognitive feature of Korsakoff's syndrome is compromised time perception. Korsakoff [11] himself noted that memory of temporal information is often more severely affected than memory of events. Similarly, Sacks (1998) described how an individual with Korsakoff's syndrome was unaware of the passing of decades. These clinical reports fit with a body of research demonstrating deviations in time perception in the syndrome. For instance, Shaw and Aggleton [12] evaluated the time reproduction of intervals between three and 96 seconds in participants with Korsakoff's syndrome. The authors demonstrated an interval of time by saying "start" and "stop", and the participants had to reproduce that interval by also saying "start" and "stop"; in another task, the participants were given the time in seconds and asked to produce this interval. Their results showed a bias toward underestimating longer intervals in these participants. These findings were observed in another study in which participants with Korsakoff's syndrome had to read numbers aloud and estimate how many seconds the reading had taken [13]. Besides this time estimation task, participants had to reproduce time intervals by indicating when they thought a predetermined time interval was over. These findings showed underestimation and under-reproduction of durations as the intervals grew longer. Similar observations were reported by Kinsbourne and Hicks [14] who instructed participants with Korsakoff's syndrome to read single digits and estimate the reading time in order to explore their ability to estimate intervals beyond 30 seconds. Compromised time perception in Korsakoff's syndrome was also observed by Brand and colleagues $[15,16]$ who asked participants with this syndrome to estimate the duration of specific activities (e.g. 'How long is the duration of a morning shower?'); once again, participants showed deficits in their time estimation of these activities.

Considering the compromised time perception in Korsakoff's syndrome, the present work investigated whether the reproduction of time intervals would be enhanced by instructing a patient with Korsakoff's syndrome to reproduce the same time interval in subsequent trials. It also aimed to enhance time reproduction by providing the patient at the end of each trial with 1) feedback on the difference between his reproduced interval and the reference interval and 2) an invitation to comply, as far as possible, with the reference interval in the next trial. By providing the patient with such feedback, we were inspired by biofeedback therapy, which consists in offering information about physiological reactions so that individuals can adjust their reactions accordingly [17].

Correspondence to: Mohamad EL HAJ, Université de Lille 3, Département de Psychologie, Domaine du Pont de Bois, B.P 60149. 59653, Villeneuve d'Ascq, France, E-mail: mohamad.elhaj@univ-lille3.fr

Key words: Korsakoff's syndrome, rehabilitation, time perception, time reproduction

Received: October 18, 2016; Accepted: December 07, 2016; Published: December 12, 2016 


\section{Method}

\section{Participant}

The present study involved Mr. L, a right-handed 61-year-old male with sixteen years of formal education. Mr. L is a French native and lives in his own home with his wife. He has a 12 -year history of worsening alcohol use. Prior to diagnosis, he was working as a health worker. Sixteen months ago, Mr. L was found unconscious at work in an alcoholic coma. During his hospitalization, he presented with severe amnesia, delirium, spatiotemporal disorientation, hallucinations, gait ataxia and nystagmus. Following admission, a formal neuropsychological assessment demonstrated retrograde amnesia. Memory impairment was indicated in both verbal and visual recall. Executive functioning deficits were also apparent. He was diagnosed with an alcohol-induced amnestic disorder (Korsakoff's syndrome) by an experienced psychiatrist, taking into account thiamine deficiency and confirming the DSM-IV-TR criteria for alcohol-induced persisting amnestic disorder. The patient reported no history of strokes, seizures, or head injury (confirmed by his wife) and the acute phase was characterized by confabulations and anterograde amnesia.

\section{Cognitive and clinical assessment}

To screen his cognitive functioning at the time of study, Mr. L was assessed using a battery measuring general cognitive functioning, episodic memory, working memory, and depression.

General cognitive functioning was assessed with the Mini Mental State Examination (MMSE) [18]; Mr. L obtained 28 out of 30 points.

Episodic memory was evaluated with a French version of the selective reminding task of Grober and Buschke (1987) [19]. In this task, Mr. L had to retain 16 words, each of which describes an item that belongs to a different semantic category. Immediate cued recall was succeeded by a distraction phase, during which the participant had to count backwards from 374 in $20 \mathrm{~s}$. This distraction phase was followed by two minutes of free recall and the score from this phase provided a measure of episodic recall (16 points maximum). Mr. L correctly remembered five words (according to the French norms of the Grober and Buschke task, his percentile was below 5\%).

For working memory evaluation, the participant had to repeat a string of single digits in the same order (i.e., forward span) or in the reverse order (i.e., backward span); his forward and backward spans were five and four, respectively.

Depression was assessed with the self-report Hospital Anxiety and Depression Scale [20], which consists of seven items scored on a four-point Likert scale ranging from zero (not present) to three (considerable); with a score of 10 points, the participant's score was below the threshold of depression (i.e., 11 points).

\section{Time perception}

A laptop computer with a 17-inch LCD display was used for testing. The software package Psychopy [21] controlled stimuli presentation and response recording. Evaluation consisted of the reproduction of intervals of 5, 10,20,30, and 40 seconds. Each time interval was assessed in three subsequent trials. It is worth noting that the assessment took place on two occasions separated by one week; on the first occasion, intervals of 5,10, and 20 seconds were assessed whereas on the second occasion, intervals of 30 and 40 seconds were assessed. Each time interval was separated by a break of approximately one minute.
At the beginning of each trial, the participant was informed that a cross would be displayed on the screen and that he had to retain the duration of the display. The participant was also instructed to reproduce the duration once the cross had disappeared. When the participant was ready, a black-colored fixation cross was displayed in the center of a gray screen for a duration of $5,10,20,30$, or 40 seconds. Following the display phase, the participant had to reproduce the duration of the previously viewed stimulus by pressing the space bar for the same duration as the stimulus was on the screen. A question mark appeared in the center of the screen as long as the participant pressed the space bar. These procedures were repeated two more times (three subsequent trials for each time interval). At the end of each trial, the participant was provided with the difference between his estimated time and the real one. He was also encouraged to reduce, as far as possible, this difference in the subsequent trial.

\section{Results}

Descriptive data about Mr. L's reproduced time in each trial for the five time intervals are presented in Figure 1. Generally speaking, Mr. $\mathrm{L}$ under-reproduced the five time intervals in all the three trials. More specifically, he demonstrated a reduction in the difference between his reproduced time and the real one across the three trials for the 5, 10, and 20 second intervals, but not for the 30 or 40 second intervals.

\section{Discussion}

This is a case study assessing the rehabilitation of time perception in a participant with Korsakoff's syndrome. The procedure consisted of asking the participant to reproduce different time intervals in three subsequent trials. At the end of each trial, the participant was provided with feedback about the difference between his estimated time and the real one. He was also encouraged to reduce, as far as possible, this difference in the subsequent trial. The participant demonstrated under-reproduction of the five time intervals in all three trials. He also demonstrated a reduction in the difference between his reproduced time and the real one (i.e., an improvement in time reproduction) across the three trials for the 5, 10, and 20 second intervals, but not for the 30 or 40 second intervals.

One consistent finding in our participant was his underreproduction of the five time intervals across the three trials. This finding fits with research showing an underestimation of time in patients with Korsakoff's syndrome [12-14]. The feeling that time passes quickly has been widely observed in normal populations. For instance, Friedman and Janssen (2010) asked a large cohort $(n=1865)$ of younger and older adults to report their subjective experience of elapsed time (e.g., how fast did the previous week pass for you?). Most participants reported experiencing time as passing quickly (for similar findings, see [22]). The impression that time passes quickly has been attributed to compromised memory $[23,24]$, an assumption that was supported by a study showing the relationship between underestimating time intervals and difficulties in subjective reliving of past events in Alzheimer's disease $[25,26]$. According to the latter study, difficulty in retrieving many events from a certain interval of time leads to the impression that this interval is shorter than actual time; in other words, by leaving fewer events to be remembered, episodic memory decline induces the feeling of an "empty" time interval, and thus the underestimation of elapsed time. The relationship between timing deviations and memory distortions can also be attributed to the involvement of the hippocampus in both cognitive declines. The classic case of H.M., who underwent a bilateral medial temporal lobe resection, demonstrates 


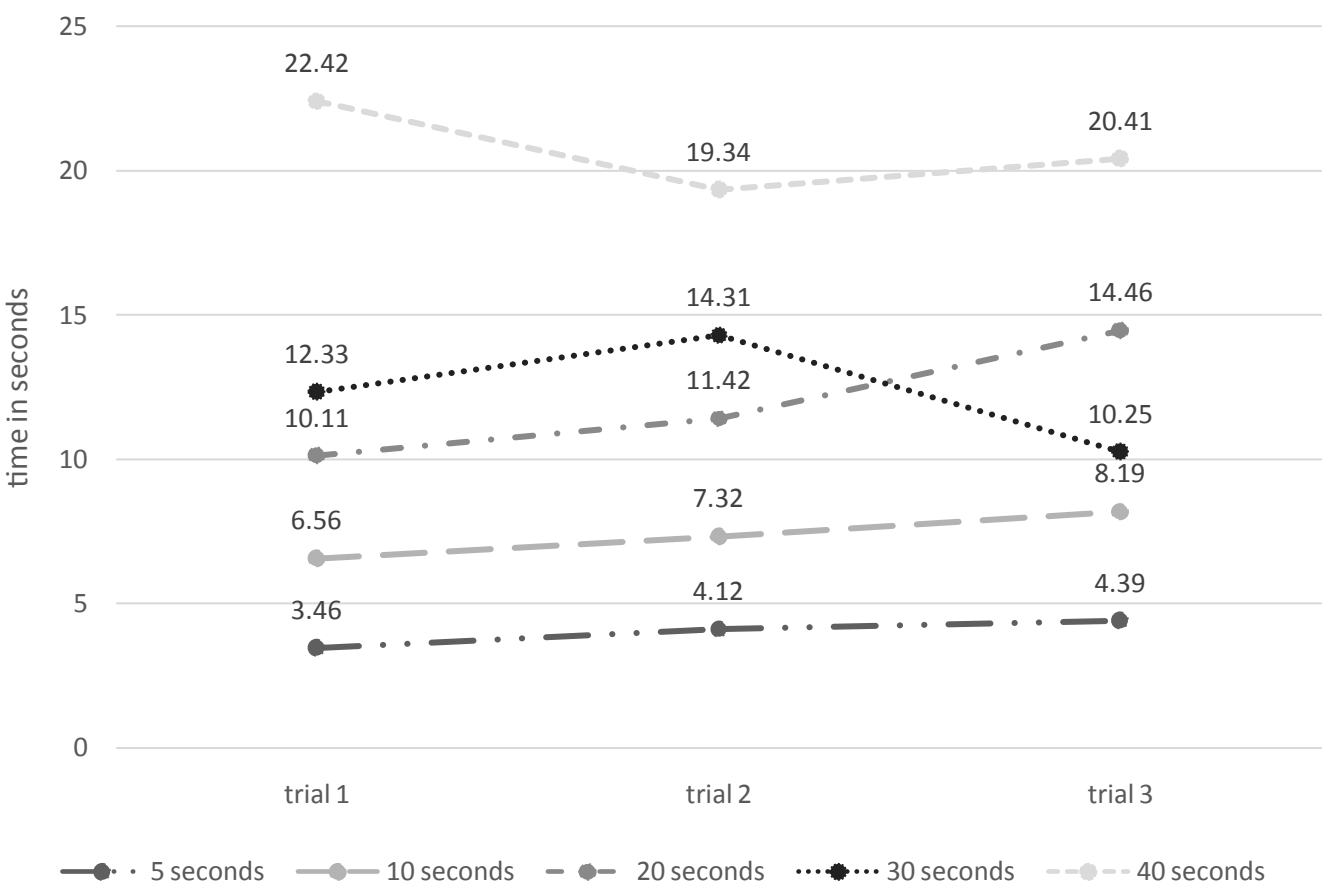

Figure 1. Reproduced time in the three trials for each of the five time intervals (i.e., 5, 10, 20, 30, and 40 seconds).

the underestimation of time [27]. In a similar vein, time distortions are also observed in amnesic patients with left medial temporal lobe lesions [28]. Another research work highlights "time cells" in the hippocampus that support time stamping and binding of sequential events in the memory $[29,30]$. Interestingly, bilateral volume deficits in the hippocampus can be observed in patients with Korsakoff's syndrome [31], which may explain time distortions in our participant. Overall, underestimation of time has been attributed to compromised memory, which is an interesting assumption as it may explain why all the five time intervals were under-reproduced across all trials in our amnesic participant.

Differences between reproduced and real time in our participant were reduced across the three trials for the 5, 10, and 20 second intervals, but not for the 30 or 40 second intervals. This finding is of interest as it demonstrates that time deviations can be alleviated in a patient with Korsakoff's syndrome for short intervals. The advantage of our procedures for short intervals, and not for longer ones, may be attributed to several factors. During the display, the participant was instructed to retain the delay but due to memory deficits, he probably forgot to retain the duration of the long intervals. Other factors, such as executive dysfunction, might also influence the reproduction of the long intervals, preventing any benefits. The executive account is of interest as time reproduction in our procedures required not only retaining the previous display time, but also waiting for the moment when the appropriate response should be provided. In other words, our participant had to hold the spacebar during the entire production interval, releasing the button at the (estimated) appropriate time, which requires significant executive resources.

Our findings demonstrate a beneficial effect of repetition and feedback on the reproduction of short intervals. These can be incorporated into research showing the beneficial effect of feedback on clinical functioning in non-demented alcohol-dependent subjects [17,32-34]. They can also be incorporated into research showing some beneficial effects of cognitive rehabilitation in Korsakoff's syndrome. There is a body of clinical research providing evidence that patients with Korsakoff's syndrome may learn procedural tasks and even reach normal levels of task performance (for a review, see [7]). It is also known that cognitive rehabilitation accelerates the improvement in cognitive functioning in the syndrome, greatly contributing to the acquisition of new abilities and the success of treatment $[35,36]$. Regardless of time perception, the effects of repetition have been also a primary focus of research on cognitive rehabilitation. One of the enduring findings in this literature is that repetition results in better retention of information and, consequently, in better learning [37]. Feedback also produces great gains in long-term retention. The effect of feedback can be attributed to the fact that it provides correction for incorrect responses, and reinforces low-confidence correct responses [38].

One may argue that a case study approach limits the generalization of results. Although this is a clear limitation, case studies provide insight into a subject prior to more complete research. Moreover, case studies address challenges associated with the analysis of a multitude of factors that are difficult to grasp with quantitative data; in the present paper, many conditions (i.e., three trials for five time intervals) were tested in an exploratory fashion and in an amnesic patient. It was hence important to test the effect of these procedures in a case study fashion prior to suggesting them for wider research. It is worth noting that several studies have adopted a case study design to reveal the beneficial effects of cognitive training on memory in Korsakoff's syndrome $[39,40]$.

One suggestion for future research would be to replicate our procedures on non-alcoholics and non-Korsakoff alcoholics. In non-alcoholics, studies have demonstrated that time perception is affected by alcohol intake [41-43]. For instance, Ogden, et al. [41] have demonstrated that a high dose of alcohol increased the speed of temporal processing, leading to over-estimations of time intervals. In a similar vein, Terry, et al. [42] have demonstrated that a high dose of 
alcohol affected time perception and production. As for non-Korsakoff alcoholics, research suggests compromise of time perception in these subjects, a compromise that has been associated with impulsivity [44]. Another suggestion is to test our procedures for five or more trials rather than for four. Future research can also consider longer or shorter time intervals between repetitions, or even other modalities of feedback (e.g., written feedback, feedback with rewards).

Overall, the present study suggests a beneficial effect of both repetition and feedback on time perception in an individual with Korsakoff's syndrome. These findings shed light not only on time distortions in amnesia but also on the rehabilitation of these distortions.

\section{References}

1. Kopelman MD (1995) The Korsakoff syndrome. Br J Psychiatry 166: 154-173. [Crossref]

2. Kopelman MD (2002) Disorders of memory. Brain 125: 2152-2190. [Crossref]

3. Pitel AL, Chetelat G, LE Berre AP, Desgranges B, Eustache F, et al. (2012) Macrostructural abnormalities in Korsakoff syndrome compared with uncomplicated alcoholism. Neurology 78: 1330-1333. [Crossref]

4. Sullivan EV, Lane B, Deshmukh A, Rosenbloom MJ, Desmond JE, et al. (1999) In vivo mammillary body volume deficits in amnesic and nonamnesic alcoholics. Alcohol Clin Exp Res 23 1629-1636. [Crossref]

5. Kril JJ, Harper CG (2012) Neuroanatomy and neuropathology associated with Korsakoff's syndrome. Neuropsychol Rev 22: 72-80. [Crossref]

6. Jung YC, Chanraud S, Sullivan EV (2012) Neuroimaging of Wernicke's encephalopathy and Korsakoff's syndrome. Neuropsychol Rev 22: 170-180. [Crossref]

7. Oudman E, Nijboer TC, Postma A, Wijnia JW, Van Der Stigchel S (2015) Procedural Learning and Memory Rehabilitation in Korsakoff's Syndrome - a Review of the Literature. Neuropsychol Rev, 25, 134-48. [Crossref]

8. Borsutzky S, Fujiwara E, Brand M, Markowitsch HJ (2008) Confabulations in alcoholic Korsakoff patients. Neuropsychologia 46: 3133-3143. [Crossref]

9. El Haj M (2016) Memory suppression in Alzheimer's disease. Neurol Sci 37: 337-343. [Crossref]

10. Brion M, Pitel AL, Beaunieux H, Maurage P (2014) Revisiting the continuum hypothesis: toward an in-depth exploration of executive functions in korsakoff syndrome. Front Hum Neurosci 8: 498. [Crossref]

11. Korsakoff SS (1889) Etude médico-psychologique sur une forme des maladies de la mémoire. Révue Philosophique 28: 501-530. [Crossref]

12. Shaw C, Aggleton JP (1994) The ability of amnesic subjects to estimate time intervals. Neuropsychologia 32: 857-873.

13. Mimura M, Kinsbourne M, O'connor M (2000) Time estimation by patients with frontal lesions and by Korsakoff amnesics. Journal of the International Neuropsychological Society 6: 517-528. [Crossref]

14. Kinsbourne M, Hicks RE (1990) The extended present: Evidence from time estimation by amnesics and normals. Cambridge University Press.

15. Brand M, Fujiwara E, Kalbe E, Steingass HP, Kessler J, et al. (2003a) Cognitive estimation and affective judgments in alcoholic Korsakoff patients. J Clin Exp Neuropsychol 25: 324-334. [Crossref]

16. Brand M, Kalbe E, Fujiwara E, Huber M, Markowitsch HJ (2003b) Cognitive estimation in patients with probable Alzheimer's disease and alcoholic Korsakoff patients. Neuropsychologia 41: 575-584. [Crossref]

17. Penzlin AI, Siepmann T, Illigens BM, Weidner K, Siepmann M (2015) Heart rate variability biofeedback in patients with alcohol dependence: a randomized controlled study. Neuropsychiatr Dis Treat 11: 2619-27. [Crossref]

18. Folstein MF, Folstein SE, Mchugh PR (1975) "Mini-mental state". A practical method for grading the cognitive state of patients for the clinician. J Psychiatr Res 12: 189-198. [Crossref]

19. Grober E, Buschke H (1987) Genuine memory deficits in dementia. Developmental neuropsychology 3: 13-36. [Crossref]
20. Zigmond AS, Snaith RP (1983) The hospital anxiety and depression scale. Acta Psychiatr Scand 67: 361-370. [Crossref]

21. Peirce JW (2007) PsychoPy--Psychophysics software in Python. J Neurosci Methods 162: 8-13. [Crossref]

22. Janssen SMJ, Naka M, Friedman WJ (2013) Why does life appear to speed up as people get older? Time \& Society 22: 274-290. [Crossref]

23. Friedman WJ, Janssen SM (2010) Aging and the speed of time. Acta Psychol (Amst) 134: 130-141. [Crossref]

24. EL Haj M, Omigie D, Moroni C (2014) Time reproduction during high and low attentional tasks in Alzheimer's Disease "A watched kettle never boils". Brain Cogn 88: 1-5. [Crossref]

25. EL Haj M, Moroni C, Samson S, Fasotti L, Allain P (2013) Prospective and retrospective time perception are related to mental time travel: evidence from Alzheimer's disease. Brain $\operatorname{Cog} n$ 83: 45-51. [Crossref]

26. EL Haj M, Kapogiannis D (2016) Time distortions in Alzheimer's disease: a systematic review and theoretical integration. Npj Aging And Mechanisms Of Disease 2: 16016. [Crossref]

27. Richards W (1973) Time reproductions by H.M. Acta Psychol (Amst) 37: 279-282 [Crossref]

28. Noulhiane M, Pouthas V, Hasboun D, Baulac M, Samson S (2007) Role of the media temporal lobe in time estimation in the range of minutes. Neuroreport 18: 1035-1038. [Crossref]

29. MacDonald CJ, Carrow S, Place R, Eichenbaum H (2013) Distinct hippocampal time cell sequences represent odor memories in immobilized rats. J Neurosci 33: 1460714616. [Crossref]

30. MacDonald CJ, Lepage KQ, Eden UT, Eichenbaum H (2011) Hippocampal "time cells" bridge the gap in memory for discontiguous events. Neuron 71: 737-749. [Crossref]

31. Sullivan EV, Pfefferbaum A (2009) Neuroimaging of the Wernicke-Korsakoff syndrome. Alcohol Alcohol 44: 155-165. [Crossref]

32. Ghosh T, Jahan M, Singh AR (2014) The efficacy of electroencephalogram neurofeedback training in cognition, anxiety, and depression in alcohol dependence syndrome: A case study. Ind Psychiatry J 23: 166-170. [Crossref]

33. Lackner N, Unterrainer HF, Skliris D, Wood G, Wallner-Liebmann SJ, et al. (2015) The Effectiveness of Visual Short-Time Neurofeedback on Brain Activity and Clinical Characteristics in Alcohol Use Disorders: Practical Issues and Results. Clinical EEG and Neuroscience. [Crossref]

34. Kirsch M, Gruber I, Ruf M, Kiefer F, Kirsch P (2015) Real-time functional magnetic resonance imaging neurofeedback can reduce striatal cue-reactivity to alcohol stimuli. Addiction Biology 982-992. [Crossref]

35. Oudman E, Van Der Stigchel S, Wester AJ, Kessels RP \& Postma A (2011) Intact memory for implicit contextual information in Korsakoff's amnesia. Neuropsychologia 49: 2848-2855. [Crossref]

36. Wilson K, Halsey A, Macpherson H, Billington J, Hill S, et al. (2012) The psychosocial rehabilitation of patients with alcohol-related brain damage in the community. Alcohol 47: 304-311. [Crossref]

37. Mulligan NW, Peterson DJ2 (2014) The spacing effect and metacognitive control. $J$ Exp Psychol Learn Mem Cogn 40: 306-311. [Crossref]

38. Butler AC, Karpicke JD, Roediger III HL (2008) Correcting a metacognitive error: Feedback increases retention of low-confidence correct responses. Journal of Experimental Psychology: Learning, Memory, and Cognition 34: 918-928. [Crossref]

39. Svanberg J, Evans JJ (2014) Impact of SenseCam on memory, identity and mood in Korsakoff's syndrome: a single case experimental design study. Neuropsychol Rehabil 24: 400-418. [Crossref]

40. Monteiro MDFA, Bolognani SAP, Rivero TS, Bueno OFA (2011) Neuropsychological Intervention in a Case of Korsakoff's Amnesia. Brain Impairment 12: 231-238. [Crossref]

41. Ogden RS, Wearden JH, Gallagher DT, Montgomery C (2011) The effect of alcohol administration on human timing: A comparison of prospective timing, retrospective timing and passage of time judgements. Acta Psychologica 138: 254-262. [Crossref] 
HAJ MEL (2016) Feedback and repetition as a tool to rehabilitate time perception in Korsakoff's syndrome: a case study

42. Terry P, Doumas M, Desai RI, Wing AM (2009) Dissociations between motor timing, motor coordination, and time perception after the administration of alcohol or caffeine. Psychopharmacology 202: 719-729. [Crossref]

43. Kunchulia M, Thomaschke R2 (2016) Effects of alcohol intake on time-based event expectations. Exp Brain Res 234: 937-944. [Crossref]

44. Cangemi S, Giorgi I, Bonfiglio NS, Renati R, Vittadini G (2010) Impulsiveness and time perception in alcohol dependent patients in alcoholic rehabilitation treatment. $G$ Ital Med Lav Ergon 32: B23-28. [Crossref]

Copyright: C2016 HAJ MEL. This is an open-access article distributed under the terms of the Creative Commons Attribution License, which permits unrestricted use, distribution, and reproduction in any medium, provided the original author and source are credited. 